\title{
Role of erlotinib in first-line and maintenance treatment of advanced non-small-cell lung cancer
}

\author{
This article was published in the following Dove Press journal: \\ Cancer Management and Research \\ 28 May 2010 \\ Number of times this article has been viewed
}

\author{
Noemí Reguart ${ }^{\prime}$ \\ Andrés Felipe Cardona ${ }^{2}$ \\ Rafael Rosell ${ }^{3}$ \\ 'Medical Oncology Service, ICMHO, \\ Hospital Clinic Barcelona, Barcelona, \\ Spain; ${ }^{2}$ Clinical and Translational \\ Oncology Group, Institute of \\ Oncology, Fundación Santa Fe de \\ Bogotá, Bogotá, D.C., Colombia; \\ Medical Oncology Service, Catalan \\ Institute of Oncology, ICO, Hospital \\ Germans Trias i Pujol, Badalona, \\ Barcelona, Spain
}

\begin{abstract}
Erlotinib hydrochloride (Tarceva ${ }^{\circledR}$ ) is a member of a class of small molecule inhibitors that targets the tyrosine kinase domain of the epidermal growth factor receptor (EGFR), with anti-tumor activity in preclinical models. Erlotinib represents a new-generation of agents known as "targeted therapies" designed to act upon cancer cells by interfering with aberrant specific activated pathways needed for tumor growth, angiogenesis and cell survival. Since its approval in November 2004 for the treatment of locally advanced or metastatic non-small cell lung cancer (NSCLC) after the failure of at least one prior chemotherapy regimen and with a view to improving patients' outcomes and prevent symptoms, the scientific community has evaluated the potential role of erlotinib in other scenarios such as in maintenance therapy and, in first-line setting for a selected population based on biological markers of response such as mutations of the EGFR. The convenient once-a-day pill administration and the good toxicity profile of erlotinib make it a reasonable candidate for testing in this context. This report provides a review of the role of erlotinib therapy in advanced NSCLC. It summarizes current data and perspectives of erlotinib in upfront treatment and maintenance for advanced NSCLC as well as looking at candidate biomarkers of response to these new targeted-agents.
\end{abstract}

Keywords: erlotinib, tyrosine kinase inhibitors, first line, maintenance, non-small-cell lung cancer

\section{Introduction}

Erlotinib is a class of the newly named "targeted therapies", designed to inhibit the epidermal growth factor receptor (EGFR) (Figure 1). The small molecule was designed to bind to the ATP pocket of the intracellular tyrosine kinase domain of the EGFR, inhibiting the phosphorylation and thereby blocking the initiation of the intracellular cascade of transduction signals. ${ }^{1,2}$ The EGFR is part of a well-known member of the TK receptors family, with key functions in regulating proliferation, apoptosis, angiogenesis and metastasis, necessary to sustain cancer cells' growth and progression in various solid tumors such as non-small-cell lung cancer (NSCLC). ${ }^{3,4}$ Erlotinib is indicated for the treatment of all subgroups of advanced NSCLC after failure of at least one prior chemotherapy regimen and for the treatment of patients with metastatic pancreatic cancer in combination with gemcitabine. ${ }^{5,6}$ This oral tyrosine kinase inhibitor (TKI) is also recommended in third-line treatment of advanced NSCLC after second-line chemotherapy failure. ${ }^{7}$ More recently erlotinib has gained another indication and has been approved as maintenance treatment for patients with locally advanced or metastatic NSCLC whose disease has not progressed after 4 cycles of platinum-based first-line chemotherapy. Erlotinib, administered once a day orally, is very convenient
Correspondence: Noemi Reguart Medical Oncology Service, ICMHO, Hospital Clinic, C/ Villarroel I70, 08036, Barcelona, Spain

$\mathrm{Tel}+34932275402$

Fax +34934546520

Email nreguart@clinic.ub.es 


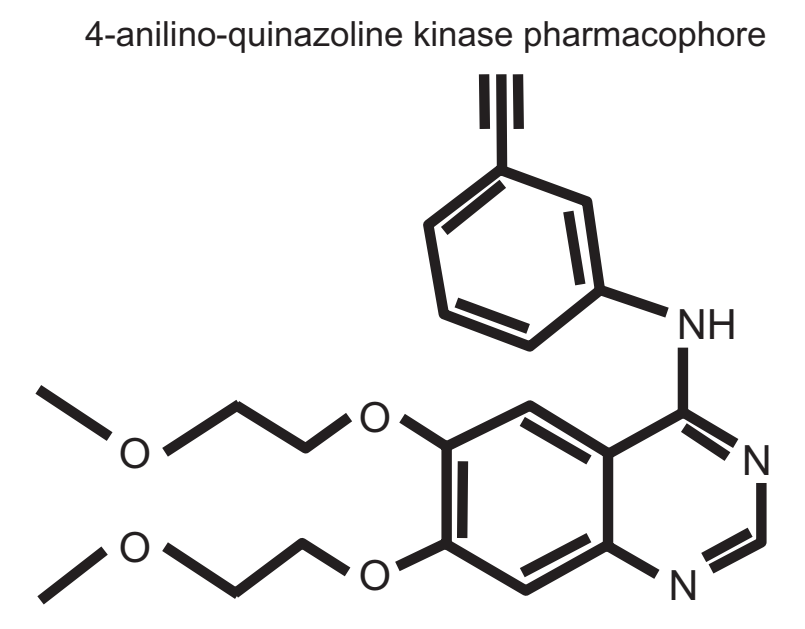

Erlotinib

Figure I Erlotinib hydrochloride molecule: $\mathrm{N}$-(3-ethynylphenyl)-6,7-bis(2methoxyethoxy)-4-quinazolinamine; $\mathrm{C}_{22} \mathrm{H}_{23} \mathrm{~N}_{3} \mathrm{O}_{4} \cdot \mathrm{HCl}$; $\mathrm{MW} 429.90$.

for patients and associated toxicities are mild, the most common being skin rash and diarrhea $(9 \%$ and $6 \%$ grade $3 / 4$ respectively). ${ }^{6}$

Lung cancer is the leading cause of cancer-related mortality ${ }^{8}$ the overwhelming majority of lung cancers, almost $80 \%$, belong to the "non-small" major histotype subgroup and about $50 \%$ of the patients are presented with extensive disease at the time of diagnosis. During the last 2 decades, we have moved from the situation in which there was believed to be no effective treatment for this distinctive aggressive disease to one in which new targeted agents have been developed along with innovative biomarkers used to identify individuals that are more likely to benefit from these therapies. This shift started in the 1980s with the first randomized trials that demonstrated the benefit of cisplatin-based chemotherapy in terms of survival, quality of life (QoL) and relieved symptoms in advanced NSCLC patients. ${ }^{9}$ Subsequently, the introduction of third-generation cytotoxic drugs to the platinum agents (known as doublets), including paclitaxel, docetaxel, gemcitabine and vinorelbine, gave rise to higher response rates (RRs) and longer overall survival (OS). ${ }^{10}$ This led to platinum doublets becoming standard in first-line advanced NSCLC treatment. With these new generation agents in advanced NSCLC, we can predict RRs of $20 \%$ to $30 \%$, with a median survival of 8 to 12 months and a 1 -year survival rate of $30 \%$ to $40 \%{ }^{10}$. Since then, other trials have demonstrated the efficacy of new cytotoxic agents such as pemetrexed, a thymidylate synthase inhibitor, ${ }^{11}$ and new targeted agents used in first-line setting combined with chemotherapy, such as bevacizumab an anti-vascular endothelial growth factor (VEGF) inhibitor or cetuximab, an EGFR inhibitor. ${ }^{12-14}$ Hence, the choice of optimal treatment for advanced NSCLC is no longer limited to the different platinum-based doublets. ${ }^{15}$ Likewise, in the second-line setting, which represents a small part of the population (around 30\%-50\% according to different phase III trials) due to clinical deterioration, ${ }^{11,12,14,16}$ prognostic improvement has been also achieved: first with the approval of single agent, docetaxel, which proved to be superior to placebo in OS and symptoms control ${ }^{17}$ and more recently with the approval of pemetrexed and erlotinib, ${ }^{18,19}$ drugs with a more favorable toxicity profile than docetaxel. However, some questions remains to be answered, such as what is be best duration of the second-line treatment and which is the optimal time to introduce them. Recently, fresh information has been gathered on the treatment of advanced NSCLC. For the first time in NSCLC, there is evidence of distinct sensitivity to chemotherapy depending on the histological subtype. ${ }^{11,19,20}$ It has been observed that in patients with squamous histology the efficacy of pemetrexed-platinum combinations is limited compared to gemcitabine combinations, whereas in non-squamous histology groups there is a benefit in OS with the addition of pemetrexed, leading the introduction of pemetrexed in first-line setting of advanced NSCLC with the indication restricted to the non-squamous subtypes. ${ }^{11,15}$ Second, the identification of molecular markers to guide the selection of specifically targeted types of therapy, ensuring better efficacy without unnecessary side effects. The most remarkable advance in this field has been the recognition of aberrant activation of the EGFR as a marker of response to TKI such as erlotinib. ${ }^{21-23}$

This review focuses specifically on erlotinib, a small molecule inhibitor of the EGFR tyrosine kinase, as part of the treatment for advanced NSCLC in two new scenarios: in the first-line setting, and as maintenance therapy continued beyond a first-line induction chemotherapy regimen. An overview of the pharmacogenomic properties of the drug in NSCLC, as well as candidate biomarkers for identifying subgroups of patients that benefit from erlotinib treatment, is also reviewed.

\section{Pharmacogenomic properties of erlotinib in NSCLC}

The EGFR family of TKs, referred to as the HER/ErbB family, consists of 4 members-EGFR (HER1/ErbB1), HER2 (ErbB2), HER3 (ErbB3) and HER4 (ErbB4)-that regulate many developmental, metabolic and physiological processes. The intracellular TK activity of EGFR is increased as a consequence of the binding of various ligands, which include EGF, transforming growth factor- $\alpha$, amphiregulin, 
epiregulin and others, leading to the homodimerization of 2 EGFRs or the heterodimerization of EGFR with other family and non-family members including HER2, HER3 and insulin growth factor receptor 1 (IGFR-1R). ${ }^{24,25}$

The activation of TK receptor leads to the autophosphorylation of the intracellular domain of the EGFR, and the phosphotyrosine residues that are formed act as a docking site for various adapter molecules, resulting in the activation of the Ras/mitogen-activated protein kinase (MAPK) pathway, the PI3K/Akt pathway and signal transducers and activators of transcription signaling pathways. ${ }^{26}$ In tumor cells, the TK activity of EGFR may be deregulated by various oncogenic mechanisms, including EGFR gene mutation, increased gene copy number and EGFR protein overexpression. ${ }^{27}$ Improper activation of EGFR TK results in increased malignant cell survival, proliferation, invasion and metastasis. ${ }^{28}$

Mutations in the EGFR have long been known to cause a constitutive, growth factor-independent activation of the EGFR downstream pathways and are frequently found in malignant diseases including brain tumors ${ }^{29}$ and NSCLC. ${ }^{21-23}$ The presence of these mutations in NSCLC correlates with responsiveness to reversible and irreversible TKIs. In a notable retrospective study, Shigematsu et al reported the genomic analysis of more than 2000 NSCLCs; EGFR mutations were found to be more common in adenocarcinoma (30\%) than in lung cancers of other histologies $(2 \%)$, and more frequent in lung cancer from never- $(45 \%)$ than ever-smokers $(7 \%){ }^{30}$

A number of distinct alterations have been identified including point mutations within the nucleotide-binding loop in exon 18, small deletions in exon 19 or insertions in exon 20 , as well as point mutations in the activation loop in exon 21. Structurally, these mutations cluster around the active site cleft of the TK domain. The two most frequent mutations are the exon 19 deletion that removes residues 746-750 of the expressed protein $(48.2 \%)$ and the exon 21 point substitution that replaces leucine 858 with arginine - L858R (42.7\%). ${ }^{31,32}$ The L858R substitution is the single most common mutation, and it lies in the activation loop (A-loop) of the kinase. Other point mutations are observed in glycine 719 , although less frequently; Gly719 is found in the adjacent phosphate-binding P-loop of the kinase, and is substituted with serine, cysteine or alanine. The L858R and G719S point mutations, as well as the exon 19 deletions and exon 20 insertions, can transform both, fibroblasts and lung epithelial cells, in the absence of exogenous epidermal growth factor. ${ }^{33-36}$

Interestingly, the clinical correlation between the presence of specific mutations and therapeutic response to TKIs is mirrored in cell lines and EGFR-transfected cells. Cells bearing the mutant EGFR are in general more sensitive to TKIs than cells expressing the wild-type kinase. In particular, the L858R mutant is 10 - to 100 -fold more sensitive to erlotinib and gefitinib than the wild-type kinase $\mathrm{e}^{22,35,37,38}$ and significantly more sensitive than the G719S mutant. ${ }^{39}$ At the same time, there are exceptions to this rule, for example the fact that the exon 20 mutants are highly resistant to both gefitinib and erlotinib further underscores the dependence of inhibitor responses on specific mutations. ${ }^{40}$

Erlotinib structure is based on the 4-anilino-quinazoline kinase pharmacophore. Crystallography studies suggests that selective inhibitors of the EGFR bind to the ATP-binding pocket, with the aniline head group fitting into the selectivity pocket of EGFR. ${ }^{41,42}$ When examined in an in vitro enzyme analysis, erlotinib has shown comparable binding affinities (Ki) values against wild-type $(3.86 \mathrm{nmol} / \mathrm{L})$ and $\mathrm{L} 858 \mathrm{R}$ mutant EGFR (4.76 nmol/L) and no significant differences in activity were found across an enzyme panel of more than 200 isolated targets (predominantly kinases). ${ }^{43}$ In the same way, erlotinib showed a high correlation in growth inhibitory activity across a panel of 34 NSCLC cell lines (Pearson's $r=0.975)$, including 3 cell lines harboring activating EGFR mutations. Similar activity was observed in the assessment of pharmacodynamic biomarkers of erlotinib activity that showed a high dose response relationship because of the inhibition of pEGFR, cell proliferation measured by inhibition of BrdU uptake, and apoptosis (annexin V labeling). ${ }^{44}$

\section{Erlotinib in first-line treatment of advanced NSCLC}

Currently, screening for common EGFR mutations in patients with NSCLC can be performed in the clinical setting to predict which patients will respond to EGFR TKIs. ${ }^{45,46}$ A seminal work recently published by the Spanish Lung Cancer Group (SLCG) demonstrates the feasibility of large-scale screening of EGFR mutations and analyzed the association between this condition and clinical outcomes to erlotinib therapy. ${ }^{46}$ From the analysis of more than 2000 NSCLC cases, mutations in the EGFR were found in 350 patients $(16.6 \%)$. The mutations were detected more frequently in women, never-smokers, and in patients with adenocarcinoma (30\%, 37.7\% and 17.3\%, respectively). Erlotinib was administered to 217 patients, of whom 113 received the TKI as first-line therapy and 104 as second- or third-line therapy. EGFR exon 19 deletions were detected in 135 cases, and the L858R point mutation in 82 tumors. The RR with erlotinib was $70.6 \%, 12.2 \%$ presented complete responses and a better outcome was associated with the exon 19 deletion than with the L858R mutation 
(odds ratio 3.08; $P=0.001) .{ }^{46}$ This registry also reveals a median progression-free survival (PFS) of 14 months, a period that was similar between patients receiving first or second-line therapy. There were no significant differences in PFS according to performance status (PS), age, first vs second or third-line therapy, or smoking history. Median OS was 27 months and the multivariate analysis found that PS 1 , male sex, the presence of the L858R mutation, brain metastases, and bronchioloalveolar adenocarcinoma were associated with poor prognosis. ${ }^{46}$

Until now, there have been no published randomized trials of EGFR TKIs vs chemotherapy as first-line therapy for NSCLC patients from Western countries; however, 2 integrative studies of phase II trials support the findings of the SLCG and promote the role of erlotinib as first-line therapy for patients with NSCLC carrying EGFR mutations. Jackman et al pooled the data of 5 first-line phase II trials designed to prove the role of erlotinib or gefitinib monotherapy in patients in whom EGFR mutations were assessed ${ }^{47}$ However, patients were customized in only one study to receive gefitinib based on the presence of this genetic condition. ${ }^{48}$ A total of 317 chemotherapy-naïve patients were treated with erlotinib or gefitinib, and tumor specimens from 223 of these patients were tested for EGFR mutations. Tumors from 84 selected patients were found to harbor a sensitizing EGFR mutation. Eighty-one percent of EGFR-mutant patients were women, $89 \%$ had adenocarcinoma, and $58 \%$ had no smoking history. Of the 84 patients harboring a sensitizing EGFR mutation treated with erlotinib or gefitinib, $67 \%$ achieved an objective response, with a median PFS of 11.8 months and a median OS of 23.9 months. ${ }^{47}$ In contrast, for 83 patients with wildtype EGFR and wild-type Kras, the RR was 5\%, the PFS was 3.1 months, and the OS was 11.8 months. Finally, in 41 patients with wild-type EGFR and mutated Kras, RR was $0 \%$, PFS was 3.3 months, and OS was 13 months. Outcomes of the 84 patients with EGFR mutations were also compared according to the EGFR directed therapy; 56 and 28 patients received erlotinib and gefitinib, respectively. There were no significant differences in RR (erlotinib 70\% and gefitinib $60 \% ; P=0.47$ ), median PFS (erlotinib 13 months and gefitinib 11.4 months; $P=0.49$ ), or OS (erlotinib 28.7 months and gefitinib 20.8 months; $P=0.10) .{ }^{47}$

Following the same perspective Paz-Ares et al added the information from twelve trials of erlotinib $(n=365)$, 39 of gefitinib $(n=1069)$ and 9 trials that assessed the role of chemotherapy (375 patients) as first-line therapy for patients with EGFR mutations. ${ }^{49}$ In the weighted pooled analysis, the overall median PFS was 13.2 months with erlotinib, 9.8 months with gefitinib, and 5.9 months with chemotherapy. Using a 2-sided permutation analysis, erlotinib and gefitinib produced a longer median PFS vs chemotherapy, both individually $(P=0.000$ and $P=0.002$, respectively) and as a combined group (EGFR TKI vs chemotherapy, $P=0.000) .{ }^{49}$

More information is available from patients with EGFR mutations treated with TKIs in Asia; recently, Mok et al reported the final data of the IPASS study (Iressa Pan-Asia Study) that found a significant interaction between treatment and EGFR mutation with respect to PFS $(P<0.001){ }^{50}$ This outcome was significantly longer among patients receiving gefitinib than among those receiving carboplatin/ paclitaxel in the mutation-positive subgroup (hazard ratio [HR] 0.48 ; 95\% confidence interval [CI] 0.36 to 0.64 ; $P<0.001)$ and significantly shorter among patients receiving gefitinib than among those receiving chemotherapy in the mutation-negative group (HR 2.85; 95\% CI 2.05 to 3.98; $P<0.001)$. Similarly, results in the subgroup with unknown EGFR-mutation status were similar to those for the overall population. ${ }^{50}$ These data were confirmed by a homologous multicenter phase II study which included 30 chemotherapy-naïve patients with poor PS who had EGFR mutations and received gefitinib alone. The overall RR was $66 \%$ (90\% CI $51 \%$ to $80 \%)$, and the disease control rate was $90 \%$. PS improvement rate was 79\% $(P<0.00005)$ and the median PFS, median OS, and 1-year survival rate were 6.5 months, 17.8 months, and $63 \%$, respectively. ${ }^{51}$

Morita et al evaluated and integrated 7 published phase II trials of gefitinib as a single first-line therapy for NSCLC patients with EGFR mutations treated in Asia and performed a pooled analysis based on individual data. ${ }^{52} \mathrm{~A}$ total of 148 patients were included; 69\% were women, $71 \%$ were neversmokers, and $97 \%$ have adenocarcinoma. The RR was significantly higher (79.3 vs $24.6 \% ; P<0.001)$, and PFS was longer (10.7 vs 6 months; $P<0.001$ ) for patients receiving the TKI than in those receiving chemotherapy, whereas there was no significant difference in OS between the two groups of patients (27.7 vs 25.7 months). ${ }^{52}$ Interestingly, the Cox regression analysis revealed that PFS after gefitinib treatment was significantly longer in the chemotherapy-naïve patients than those who had received previous chemotherapy. This result highlights the fact that first-line chemotherapy could have a detrimental effect on the later use of EGFR TKIs in NSCLC patients harboring EGFR mutations. ${ }^{53}$ Currently there are 2 ongoing phase III trials, which aim to give more insights into the role of the erlotinib in the first-line setting of patients harboring EGFR mutations (Figures 2 and 3): the 


\section{Phase III study initiated by the Spanish Lung Cancer Group (GECP) recruitment ongoing in Spain, Italy and France}

- Chemo-nal̈ve advanced NSCLC

- EGFR mutation-positive

(exon 19 or L858R)

- ECOG PS 0-2

- $\mathrm{n} \sim 150$

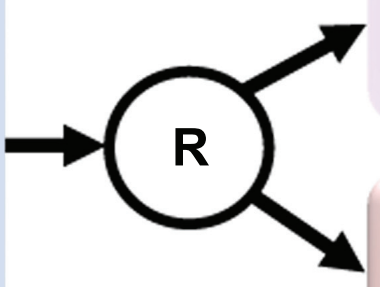

Erlotinib $150 \mathrm{mg} /$ day until PD

Primary end-point: PFS

Secondary end-points: ORR, 1-year survival, OS, safety, QoL, localization of PD

Figure 2 Design of the phase III trial of erlotinib in first-line advanced NSCLC with EGFR mutations in Europe: the EURTACC trial. ${ }^{54}$

Abbreviations: ECOG, Eastern Oncology Cooperative Group; EGFR, epidermal growth factor receptor; NSCLC, non-small-cell lung cancer; ORR, objective response rate; PD, progressive disease; QoL, quality of life.

EURTAC trial (NCT00446225), ${ }^{54}$ from European countries, and the OPTIMAL trial (NCT00874419) in Asia. ${ }^{55}$ Both trials randomized chemotherapy-naïve NSCLC EGFR-mutant patients to receive erlotinib vs chemotherapy, PFS being the primary end-point in both studies.

\section{Role of erlotinib as maintenance therapy in advanced NSCLC}

Erlotinib was the first new class of drugs against a specific molecular target directed to a TK that demonstrate singleagent activity in advanced NSCLC patients. Erlotinib was first evaluated in a randomized, double-blind, placebo-controlled trial with 731 patients with advanced NSCLC who had previously received one or more prior chemotherapy regimens (BR.21). ${ }^{18}$ Patients were randomized to receive either oral erlotinib $150 \mathrm{mg} /$ daily or a placebo. The primary end-point was OS that favor the group of patients treated with erlotinib (6.7 months vs 4.7 months; $P<0.001$ ) with an adjusted HR of 0.70 (95\% CI 0.58 to 0.85 ). The benefit in survival was consistent among the different patient subgroups based on sex, histology and smoking habits. However, patients neversmokers got more benefit than did smokers (HR 0.42 and 0.87 , respectively). ${ }^{56} \mathrm{RR}$ and PFS were also significantly higher $(P<0.001)$ with erlotinib than with the placebo group

\section{Phase III study initiated by Tongji University, Shanghai, China recruitment ongoing in China}

- Chemo-naïve advanced NSCLC

- EGFR mutation-positive

(exon 19 or 21)

- $\quad$ ECOG PS 0-2

- $\mathrm{n} \sim 150$

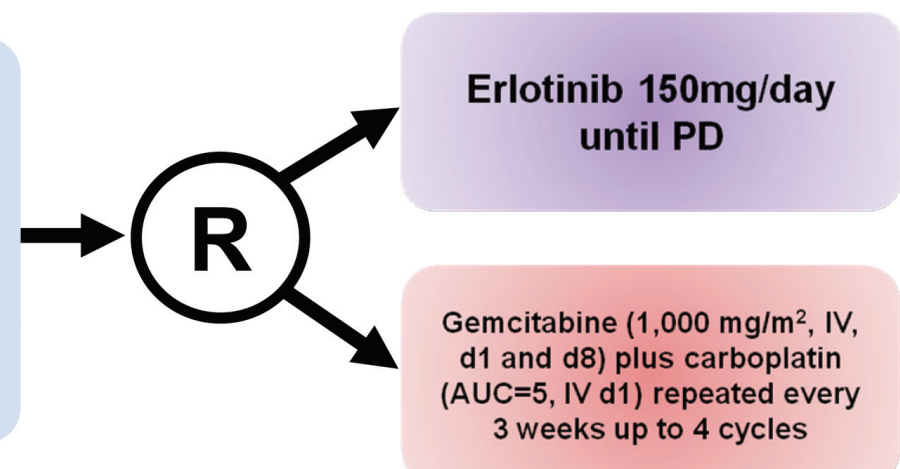

Primary end-point: PFS

Secondary end-points: ORR, OS, QoL and safety

Figure 3 Design of the phase III trial of erlotinib in first line advanced NSCLC with EGFR mutations in Asian population: the OPTIMAL trial. ${ }^{55}$

Abbreviations: ECOG, Eastern Oncology Cooperative Group; EGFR, epidermal growth factor receptor; NSCLC, non-small-cell lung cancer; PD, progressive disease; PFS, progression-free survival; ORR, overall response rate; OS, overall survival; QoL, quality of life. 
( $8.9 \%$ vs $1 \%$ and 2.2 vs 1.8 months respectively) and although the side effects were higher in the erlotinib arm, most adverse events were mild or moderate. ${ }^{18}$ On the basis of data from the BR21 trial, ${ }^{18}$ erlotinib was approved by the US Food and Drug Administration (FDA) in November 2004 for the treatment of all subtypes of advanced NSCLC after failure of at least one prior chemotherapy regimen. ${ }^{6}$ At the moment, together with docetaxel and pemetrexed, erlotinib remains the standard of treatment in second-line advanced NSCLC. Nonetheless, one question remains unanswered; it is not yet known which of the three drugs approved in second-line treatment should be selected, unless the criterion of toxicity profile is applied. A randomized phase III biomarker validation study of secondline therapy of erlotinib versus pemetrexed in patients with advanced NSCLC (NCCTG-N0723) aims to shed some light on this issue. ${ }^{57}$

Currently, second-line treatment in advanced NSCLC is indicated if there is a relapse or disease progression after the first-line platinum-based combination and most patients who are treated with first-line chemotherapy will experience disease progression within 3 or 4 months. ${ }^{10}$ The term "maintenance" therapy is usually used when one of the drugs used in the upfront combination treatment is maintained beyond the initial 4 to 6 cycles of chemotherapy, generally as firstline treatment, until disease progression or unacceptable toxicity (Figure 4). The continuous administration of therapy after the recommended 4 to 6 treatment cycles is used with patients for whom the treatment has been demonstrated to be effective, ie, patients with a stabilization or tumor response with the up-front chemotherapy, which accounts around $75 \%$ of the treated population. There is some semantic controversy surrounding the use of the word "maintenance" and the switch to another non-cross resistant drug early after first-line therapy without progression is also referred to as "early second-line" or "consolidation" therapy. In advanced NSCLC, there has been a renewed interest in assessing both the duration of the up-front treatment as well as when to start the second-line treatment. It is worth mentioning that in advanced NSCLC, there is no standard approach to follow-up the tumor growth and consequently there is concern about our ability to detect disease progression before it impairs patient's condition. When lung cancer patients experience tumor growth their physical condition promptly deteriorates due to the distinctive aggressive behavior of this disease, restricting the options for further treatments. ${ }^{11,12,14,16}$ Therefore the rationale of the maintenance therapy approach is to improve the outcomes, by maintaining the initial responses to the platinum-doublet therapy, as well as the QoL, by delaying cancer-related symptoms.

Several old trials investigated the role of longer platinumbased combinations with old cytotoxic agents and failed to demonstrate a survival advantage. ${ }^{58-63}$ The idea of "the more

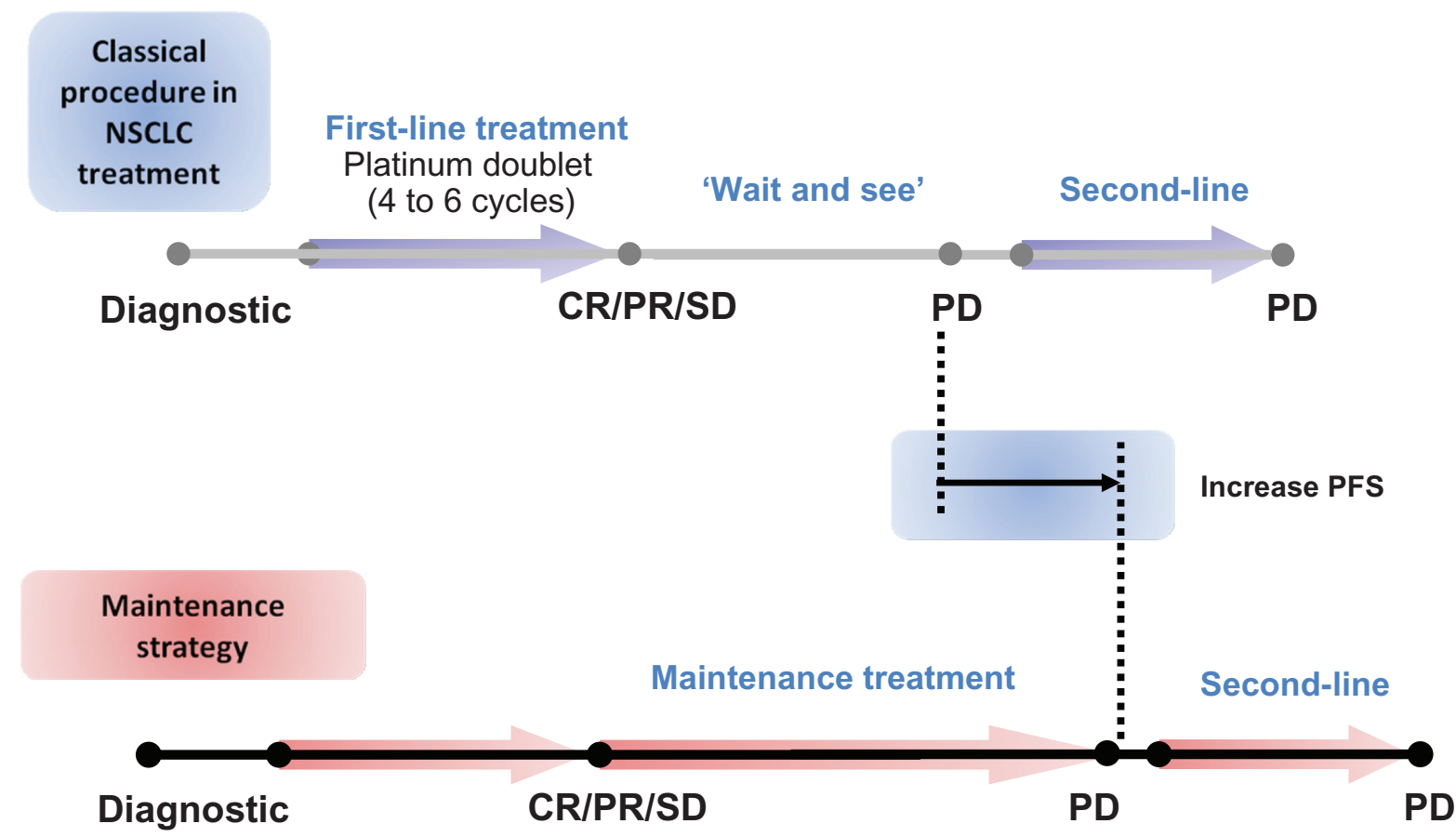

Figure 4 Current strategies to treat advanced NSCLC patients.

Abbreviations: NSCLC, non-small-cell lung cancer; PD, progressive disease; CR, complete response; PR, partial response; SD, stable disease. 
chemotherapy the better" was finally laid to rest with a recent meta-analysis which corroborated the absence of a survival advantage in advanced NSCLC with the continuation of the same platinum-based chemotherapy beyond the standard 4 to 6 cycles in first-line setting. ${ }^{64}$ The meta-analysis performed with PFS as end-point $(n=1907)$ showed the advantage in PFS with extending chemotherapy duration, more evident when a third-generation agent was used, ${ }^{64}$ but it is worth noting that QoL analysis was not assessed in all the trials and in the few in which it was, a trend to worsening QoL, in terms of chemotherapy-related side effects, was observed with more chemotherapy. ${ }^{62-64}$ However, one has to bear in mind that toxicity profiles of the drugs used in these trials were worse than the ones related to new third-generation cytotoxic and targeted agents. Consequently the use of third-generation cytotoxic agents or targeted therapies with a better toxicity profile and more convenient administration are attracting interest, as they could avoid the development of cancerrelated symptoms by controlling tumor growth without the undesirable toxicities associated with the long-term use of cytotoxic agents. Moreover, the use of molecularly targeted therapies (such as erlotinib) as maintenance raise the possibility of a more specifically molecular-guided tumor approach based on the distinctive biological features of each tumor.

The maintenance approach with targeted therapies was initially considered in trials that valued the role of the concurrent addition of new targeted agents to chemotherapy as a way of seeing whether they could improve outcomes in advanced NSCLC patients. ${ }^{16,65-67}$ In these trials maintenance with the targeted agent after induction was allowed until unacceptable toxicity or disease progression set in, on the grounds that they would delay disease progression with a good tolerability profile (Table 1). The TRIBUTE trial, ${ }^{65}$ a randomized, doubleblind, phase III trial, assigned chemotherapy-naïve advanced NSCLC patients with good PS to receive orally erlotinib $150 \mathrm{mg} /$ daily or a placebo combined with up to 6 cycles of carboplatin plus paclitaxel. In the Tarceva Lung Cancer Investigation Trial (TALENT) ${ }^{16}$ patients received $150 \mathrm{mg}$ of oral erlotinib daily or a placebo, combined with up to 6 gemcitabine platinum-based combinations. Both trials failed to demonstrate their main objective and provided no evidence of a survival advantage with erlotinib added to the cisplatin combination, ${ }^{16,65}$ or for maintenance with erlotinib. The same holds true for the gefitinib trials in first line with chemotherapy. ${ }^{66,67}$ However in the TALENT trial, although the proportion of patients with objective responses was similar for the erlotinib and placebo arm (31.5\% vs $29.9 \%$, respectively), the duration of the response (though not the median time to symptomatic progression) in the experimental arm with erlotinib was small but significantly greater (median 25.4 vs 23.9 weeks; HR 0.77; $P=0.045$ ). ${ }^{16}$ The FAST-ACT (First Asian Sequential Tarceva and Chemotherapy Trial) is a first-line randomized phase II trial of an intermittent erlotinib (days 15 to 28) and gemcitabine platinum-based combination (GC) in a majority of the Asian population. ${ }^{68}$ In this trial, responding patients were also permitted to continue with erlotinib or placebo until there was disease progression or unacceptable toxicity. The trial did not achieve its main objective to improve the non-progression

Table I Randomized trials of maintenance therapy with erlotinib

\begin{tabular}{|c|c|c|c|c|c|c|c|}
\hline Author & Trial design & Phase & $\begin{array}{l}\text { Pts included } \\
\text { (randomized) }\end{array}$ & $\begin{array}{l}\text { RR (during } \\
\text { maintenance) }\end{array}$ & PFS & os & $\begin{array}{l}\text { QoL } \\
\text { FACT-L }\end{array}$ \\
\hline Capuzzo $o^{75,76}$ & $\begin{array}{l}\text { Erlotinib vs placebo } \\
\text { after platinum based } \\
\text { chemotherapy (SATURN) }\end{array}$ & III & 1949 (889) & $\begin{array}{l}12 \% \text { vs } 5 \% \\
(P=0.0006)\end{array}$ & $\begin{array}{l}\text { I } 2.3 \text { vs II.I weeks } \\
(P<0.000 \text { I })\end{array}$ & $\begin{array}{l}\text { I } 2.3 \text { vs II.I months } \\
(P=0.0088)\end{array}$ & $\begin{array}{l}\text { pain and } \\
\text { analgesic use } \\
\text { delayed ( } P \text { ns) }\end{array}$ \\
\hline Miller ${ }^{74}$ & $\begin{array}{l}\text { Bevacizumab with } \\
\text { or without erlotinib } \\
\text { after platinum-Bevacizumab } \\
\text { based chemotherapy } \\
\text { (ATLAS) }\end{array}$ & III & II 60 (768) & NR & $\begin{array}{l}4.8 \text { vs } 3.7 \text { months } \\
(P=0.00 \mid 2)\end{array}$ & NR & NR \\
\hline Mok $^{68}$ & $\begin{array}{l}\text { Sequential erlotinib } \\
\text { vs placebo plus cisplatin- } \\
\text { gemcitabine (FAST-ACT) }\end{array}$ & II & 154 & NR & $\begin{array}{l}29.4 \text { vs } 23.4 \text { weeks } \\
(P=0.0002)\end{array}$ & $\begin{array}{l}74.1 \text { vs } 75.7 \text { weeks } \\
(P \text { ns })\end{array}$ & NR \\
\hline Herbst $^{65}$ & $\begin{array}{l}\text { Erlotinib vs placebo plus } \\
\text { carboplatin-paclitaxel } \\
\text { (TRIBUTE) }\end{array}$ & III & 1059 & NR & $\begin{array}{l}5.1 \text { vs } 4.9 \text { months } \\
(P \mathrm{~ns})\end{array}$ & $\begin{array}{l}\text { I0.6 vs } 10.5 \text { months } \\
(P \text { ns })\end{array}$ & NR \\
\hline Gatzemeier ${ }^{16}$ & $\begin{array}{l}\text { Erlotinib vs placebo plus } \\
\text { cisplatin-gemcitabine } \\
\text { (TALENT) }\end{array}$ & III & 1172 & NR & $\begin{array}{l}23.7 \text { vs } 24.6 \text { weeks } \\
(P \text { ns })\end{array}$ & $\begin{array}{l}43 \text { vs } 44 . I \text { weeks } \\
(P \text { ns })\end{array}$ & NR \\
\hline
\end{tabular}

Abbreviations: Bvz, bevacizumab; QoL, quality of life; OS, overall survival; PFS, progression-free survival; RR, response rate; Pts, patients; ns, non-significant; NR, notreported. 
rate at 8 weeks with the "pulsed" administration of erlotinib (80.3\% GC-erlotinib vs 76.9\% GC-placebo, $P=0.5143$ ) and there were no significant differences in the RR between groups (35.5\% GC-erlotinib vs 24.4\% GC-placebo, $P=0.12$ ). However, there was a significant $(P=0.0002) 53 \%$ improvement in PFS (29.4 vs 23.4 weeks; HR 0.47) which favors the erlotinib plus chemotherapy group. ${ }^{68}$ Although the majority of patients included in the trial were Asian, the observed PFS benefit was consistent across all the predefined clinical subgroups, including smokers, males and non-adenocarcinoma tumor patients.

Other trials with other targeted agents such as bevacizumab or cetuximab, ${ }^{12-14}$ allowed the continuation of the targeted agent after completion of the combination chemotherapy and the targeted agent. However these trials were not initially designed to evaluate the efficacy of maintenance with the targeted agent, and there is no valid control arm for the maintenance part of the trials. The data from these trials indicate that continuation with the targeted agent is feasible, but they do not provide data about the incremental benefit of continuing the targeted agent beyond completion of the initial treatment. Therefore the question of whether maintenance with cetuximab or bevacizumab is helpful in this setting remains unanswered until well-designed phase III trials are carried out.

The concept of consolidation, using a non-cross agent treatment started before tumor progression, also referred to as an "early second-line", has been investigated in several trials. ${ }^{20,69}$ The prompt use of a different agent to the ones used for the induction treatment has some potential advantages. Some authors ${ }^{70-72}$ suggest that the prompt switch to another non-cross resistant agent may reduce the risk of development resistant clones that increases over time. Therefore, those patients shown to benefit from the upfront treatment with a platinum doublet would be candidates for a maintenance approach. Consolidation with chemotherapy has recently been evaluated; Fidias et a ${ }^{69}$ could not demonstrate a statistically significant advantage in OS for patients treated immediately with docetaxel, started after completion of the first-line treatment with carboplatin and gemcitabine, compared to the conventional initiation after disease progression. There were no differences in QoL between the two groups and a highly significant benefit in terms of PFS (5.7 vs 2.7 months; HR 0.71 ) and a trend towards better survival (12.3 vs 9.7 months; $P=0.08$ ) was observed for the randomly assigned patients in the immediate docetaxel arm as an "early second line". However when patients not receiving docetaxel late second line were excluded $(n=98)$, OS was identical for both groups (12.5 months). More recently the JMEN trial, ${ }^{20}$ a randomized phase III trial, has released results showing, for the first time, an advantage in terms of OS for a maintenance strategy in NSCLC. The trial assigned patients to receive pemetrexed versus placebo as maintenance after the induction with 4 cycles of a platinum combination that did not include pemetrexed. The study achieved its end-point and demonstrated a highly significant $(P<0.0001)$ benefit in terms of PFS (4.3 vs 2.6 months; HR 0.50) and OS (13.4 vs 10.6 months; HR 0.79, $P=0.012$ ) with the immediate initiation of pemetrexed. ${ }^{20}$ However it is worth mentioning that the trial was not designed to test the superiority in OS of pemetrexed over placebo and only $18 \%$ of patients in the placebo arm ever received pemetrexed as systemic post-discontinuation therapy. Interestingly, the subset analysis by histology suggested that squamous tumors do not benefit from maintenance with pemetrexed in terms of PFS and OS. ${ }^{20}$

The use of targeted agents has also been evaluated in consolidation. Unlike cytotoxic agents such as intravenous chemotherapy, these targeted treatments may be more appealing in the maintenance setting and thus are generally well tolerated and have a more convenient oral administration for patients. Moreover, treatment with targeted therapies may overcome the undesirable cumulative toxicity caused by cytotoxic agents administered in first-line setting. On the other hand, the cytostatic rather than cytotoxic properties of the new targeted drugs makes them a potential candidate for use in patients who have already shown a response after the initial chemotherapy by maintaining the tumor responses and delaying the progression event. In 2009, the results of 2 major phase III studies, ATLAS and SATURN, which evaluated the role of the TKI erlotinib as single-agent maintenance therapy in advanced NSCLC either with of without bevacizumab, an anti-VEGF receptor, were released in the annual American Society of Clinical Oncology meeting. ${ }^{73,74}$ These trials offered the possibility of continuing an active treatment with erlotinib after completing chemotherapy in order to delay disease progression and symptom deterioration. SATURN (Sequential Tarceva in Unresectable NSCLC) ${ }^{73}$ is a randomized, placebo-controlled phase III trial in which erlotinib was evaluated as first-line maintenance therapy in advanced NSCLC patients whose disease had not progressed after 4 cycles of a platinum-doublet treatment. In this trial patients received erlotinib (150 mg/ day) or placebo until disease progression or unacceptable toxicity, if disease control (stable disease, partial response or complete response) was documented after the 4 initial cycles of chemotherapy (Figure 5). Tissue samples of the randomized patients were collected at baseline. The primary end-points were to determine whether the administration of erlotinib, as 

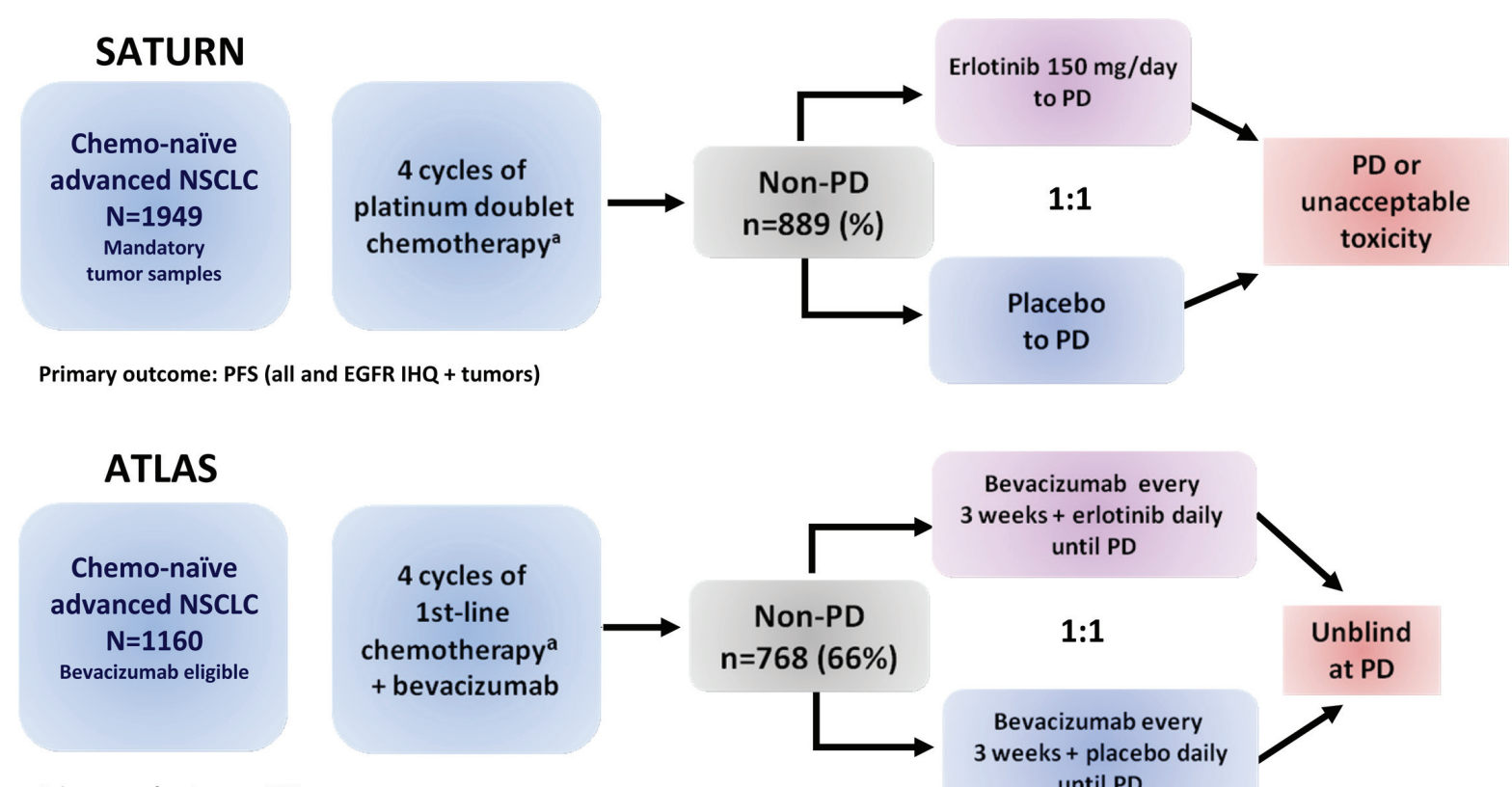

Primary end outcome: PFS

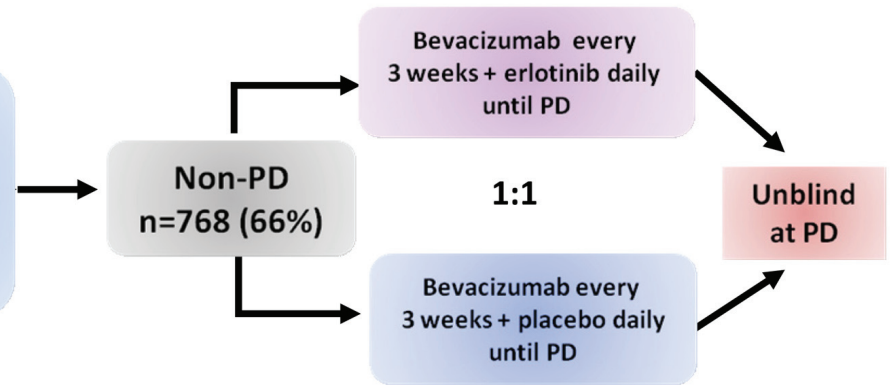

${ }^{a}$ Carbo/paclitaxel; cis/vinorelbine; carbo or cis/gemcitabine; carbo or cis/docetaxel.

Figure 5 Design of erlotinib maintenance phase III trials in advanced NSCLC treatment (SATURN ${ }^{73}$ and ATLAS $^{74}$ ).

Abbreviations: NSCLC, non-small cell lung cancer; non-PD, complete responses, partial responses, stable disease; PD, progressive disease; PFS, progression-free survival.

maintenance after the standard platinum-based chemotherapy, increases PFS in all patients and in those whose tumors express EGFR by inmunohistochemistry (IHQ). Secondary end-points included determining OS throughout the population and in patients according to protein expression of EGFR, as well as the analysis of other different biomarkers (EGFR gene copy number by fluorescent in situ hybridization - FISH, EGFR and Kras mutations with intron $1 \mathrm{CA}$-repeat polymorphism at EGFR by sequencing). Among the 889 patients randomized, out of a total of 1949, PFS (assessed by an investigator and an independent review and defined as the length of time from randomization to disease progression or death from any cause) was significantly prolonged with erlotinib versus placebo (HR $0.71 ; 95 \%$ CI 0.62 to $0.82 ; P<0.0001)$. There was a $41 \%$ improvement in PFS but the absolute differences were less than we might have hoped (12.3 vs 11.1 weeks). The percentage of patients without progression at 3 and 6 months were 53\% vs $40 \%$ and $31 \%$ vs $17 \%$ for the erlotinib and the placebo group respectively. In patients whose tumors expressed EGFR by IHQ ( $\mathrm{n}=618$ ), the absolute benefit for erlotinib was $45 \%$ (HR $0.69 ; 95 \%$ CI 0.58 to $0.82 ; P<0.0001)$. Although the advantage in PFS was observed for all the subgroups of population analyzed (HR 0.71), mean PFS was significantly increased by 1 month (3.75 vs 4.76 months; HR 0.72) in women, people with Asian ethnicity and never-smokers. It is worth mentioning that although the patients included in the trial had already responded to the induction chemotherapy, maintenance with erlotinib achieved an overall RR of $12 \%$ vs $5 \%$ in the placebo group $(P=0.0006)$ and the disease control rate after 12 weeks of treatment, in the erlotinib group, was almost double that of the placebo arm $(40.8 \%$ vs $27.4 \%, P=0.0001)$. In general, erlotinib was well tolerated; the withdrawals from the study due to treatment-related adverse events were mild without differences in both groups and the major treatment-related toxicities were the anticipated grade I/II rash and diarrhea. Nevertheless, the assessment of QoL by the FACT-L (Functional Assessment of Cancer Therapy-Lung questionnaire) provided no evidence of a significant benefit, or impairment, in QoL with the active treatment (HR 0.96, 95\% CI 0.79 to $1.16 ; P=0.6530$ ), and only pain and analgesic use seemed to be significantly delayed with the erlotinib manteinance. ${ }^{73}$

Later in the year, the much anticipated final results on survival were released at the 13th World Conference of Lung Cancer and the 34th ESMO congress. ${ }^{75,76}$ Maintenance with erlotinib significantly increased OS vs placebo in the intention-to-treat advanced NSCLC patients (HR 0.81, $95 \%$ CI 0.70 to $0.95 ; P=0.0088$ ), but as observed for PFS, the absolute differences in OS with erlotinib were minor (12.3 vs 11.1 months). However, OS differences for non-squamous disease treated with erlotinib appeared more worthwhile (13.7 vs 10.5 months, HR $0.79 ; P=0.01$ ). Among subgroup analysis, the greatest advantage in OS was observed for 
women (HR 0.64), people with Asian ethnicity (HR 0.66), never-smokers (HR 0.69) and adenocarcinoma tumors (HR 0.77), although all the subgroups of population analyzed gain a survival benefit from erlotinib maintenance. Interestingly, the magnitude of the benefit was greater in patients with stable disease following first-line chemotherapy than in those achieving a complete or partial response. Erlotinib, compared with placebo, gave patients with stable disease a $39 \%$ improvement in OS and a 2.3 -month improvement in median survival (11.9 months vs 9.6 months; HR 0.72; $P=0.0019)$. Based on these results the European Commission (EMEA) has approved erlotinib as monotherapy for maintenance treatment in patients with locally advanced or metastatic NSCLC with stable disease following 4 cycles of standard platinum-based first-line chemotherapy.

The initial planned biomarker assessment revealed that the benefit on PFS was observed in all patients subgroups regardless EGFR or Kras mutation status. ${ }^{77}$ Some groups benefited disproportionally from erlotinib such as EGFR positive by IHQ (HR 0.69) or by FISH (HR 0.68) and wild type Kras (HR 0.70). On the other hand, the strongest benefit in PFS was observed for the 49 patients with mutation at EGFR exon 19 or 21 (HR $=0.10 ; 95 \%$ CI 0.04 to $0.25 ; P<0.0001$ ), whereas EGFR wild type tumors seemed to benefit more from the erlotinib treatment (HR 0.77) compared to EGFR mutated tumors (HR 0.83). ${ }^{77}$ These confusing results might be explained by the high level (67\%) of subsequent EGFR tyrosine kinase inhibitor use in the placebo arm after progression in the EGFR mutated group, by the immature data on OS or by the unrepresentatively small sample in the subset analysis $(n=49)$. Meanwhile, multivariate analyses are needed for biomarker analysis as many of these biomarker-selected groups may overlap.

The randomized, double-blind, placebo-controlled, phase IIIB ATLAS (Adjuvant Tamoxifen Longer Against Shorter) trial, comparing bevacizumab therapy with or without erlotinib, after completion of chemotherapy with bevacizumab for the treatment of locally advanced, recurrent, or metastatic NSCLC, is the second important trial designed to assess the role of maintenance with bevacizumab with or without erlotinib $^{74}$ (Figure 5). Patients were initially treated with 4 cycles of bevacizumab in combination with the investigators' choice of platinum-based chemotherapy regimens. If their cancer did not progress and they did not experience significant toxicity, patients were then randomized $(n=768)$ to receive maintenance therapy with bevacizumab $(15 \mathrm{mg} / \mathrm{kg})$ plus erlotinib $(150 \mathrm{mg} /$ day) or placebo until disease progression. Patients with treated brain metastases, those receiving anticoagulation treatment with low-molecular-weight heparin and peripheral squamous tumors were also eligible for the study. The primary objective of the study was PFS started from the beginning of the maintenance phase after initial treatment with chemotherapy and bevacizumab, and the secondary included safety assessment and OS. The ATLAS study was prematurely stopped on the recommendation of an independent data safety monitoring board after a pre-planned interim efficacy analysis showed the study met the primary end-point and that combining erlotinib and bevacizumab significantly extended the time patients live without disease progression compared to bevacizumab plus placebo. ${ }^{78}$ The preliminary safety analysis also gave evidence of a safe toxicity profile with adverse events consistent with other previous studies of bevacizumab and erlotinib and no new safety signals were observed. The median PFS was 4.8 months for bevacizumab and erlotinib vs 3.7 months for bevacizumab without erlotinib (HR $0.72,95 \%$ CI 0.59 to $0.88 ; P=0.0012$ ). The percentage of patients without progression at 3 months was $67 \%$ for the erlotinib group vs $53 \%$ for the placebo group and at 6 months was $40 \%$ and $28 \%$ respectively. ${ }^{74}$ The results on OS are expected for the first half of 2010. The trial included a prospective analysis of several biomarkers, ${ }^{79}$ EGFR IHQ, gene copy number by FISH and EGFR and Kras mutations by sequencing. The results suggest that EGFR FISH positive (HR 0.66), EGFR mutated (HR 0.44) and Kras wild type (HR 0.67) patients, could derive the greatest improvement in PFS with bevacizumab and erlotinib. ${ }^{79}$

\section{Resistance to erlotinib in EGFR mutant patients and future therapeutic strategies}

In NSCLC patients carrying EGFR mutations the treatment with first generation TKIs provides dramatic clinical and radiological responses; overall, EGFR mutations carriers have a RR around $75 \%$, compared with a RR lower than $10 \%$ for patients with wild type EGFR. ${ }^{80}$ Furthermore, patients with EGFR mutations have been shown to have longer progression-free and OS. ${ }^{46}$ Despite this encouraging data, almost all cases invariably develop "acquired" resistance to TKIs, ${ }^{40}$ which means the progression of the tumor that had previously responded to the treatment. About $43 \%$ to $50 \%$ of cases with acquired resistance to reversible EGFR TKIs can be accounted for by a secondary mutation, the gatekeeper mutation T790M located in exon 20 of the EGFR kinase domain. ${ }^{81}$ This acquired alteration increases the ATP binding affinity of EGFR approximately 10 -fold in the presence or absence of a TKI allowing ATP to competitively 
displace gefitinib and erlotinib from EGFR. ${ }^{82}$ At least 10 other activating mutations (less common single amino acid substitutions such as D761Y, L747S, and T854A) have been reported within the kinase domain and the novel E884K mutation has been associated with resistance to gefitinib and erlotinib. ${ }^{83}$

Balak et al noted that given the proportion of patients with acquired resistance, whose tumors contain T790M, malignant cells remain dependent on mutant EGFR for survival in at least half of patients. ${ }^{84}$ On the other hand, the T790M mutation can also be detected in pretreatment specimens (38\%), a condition that was associated with a short PFS (7.7 months vs 16.5 months in those without the mutation; HR for progression for the T790M allele, $11.5 ; P<0.001) .{ }^{85}$ All these aspects provide a rationale for developing second generation of irreversible TKIs, such as HKI-272, EKB-569, CI-1033 and BIBW2992, that bind covalently with the catalytic pocket of the TK receptor providing a sustained blockade against tumors harboring the T790 mutation. ${ }^{86}$ Currently some phase II clinical trials with second-line TKIs, suggest a RR as high as 50\% in some small cohorts, although only stable disease at best has been documented in patients with known T790M mutations. ${ }^{87-89}$

Another $20 \%$ of cases of acquired TKI resistance involve amplification of the MET proto-oncogen..$^{90}$ In this resistant tumors, amplification of MET activates PI3K-AKT signaling through erbB3. ${ }^{90}$ IGFR-1R is another potential mechanism of escape to the therapeutic effect of TK reversible inhibitors. ${ }^{91}$ Heterodimerization of the EGFR/IGFR-1R stimulates downstream pathways such as PI3K/AKT and MAPK, resulting in mammalian target of rapamycin (mTOR)-mediated protein synthesis of EGFR in NSCLC cells. ${ }^{92,93}$ These preclinical studies support the rational for clinical trials designs with combined treatment of a reversible TKI along with MET kinase, IGFR-1R or mTOR inhibitors. This approach could further improve the current results obtained with a singleagent in a subgroup of NSCLC patients with EGFR mutations and acquired resistance. ${ }^{94}$

As reversible EGFR TKIs are now established as standard first-line therapy for patients with lung cancer with EGFR mutation, thoracic oncologists expect to see more patients with acquired resistance. ${ }^{50}$ To simplify the definition of acquired resistance, recently Jackman et al proposed 4 easy and largely clinical criteria relevant to clinicians in their regular practice and to researchers in their design of studies..$^{95}$ The first criterion relates to patients who had previously received treatment with single-agent EGFR TKI; the second, that the tumor meet one or other of the following items: (A) that it harbors an EGFR mutation known to be associated with drug sensitivity; or (B) the patients do present clinical benefit from treatment with EGFR TKI (ie, either documented partial or complete response (RECIST or WHO), or a significant and durable ( $>6$ months) stable disease after initiation TKIs); thirdly, there must be some evidence of systemic progression of disease while on continuous treatment with gefitinib or erlotinib within the last 30 days; and finally, that there is no intervening systemic therapy between cessation of the TKI and initiation of new therapy. ${ }^{95}$ However, there is a small subgroup of EGFR mutant patients with primary, poorly understood resistance $(6.5 \%$ to $10 \%)$ who never respond to first-line TKI therapy. ${ }^{96}$

\section{Conclusions}

As highlighted by this review, erlotinib is an oral TKI with demonstrated activity in NSCLC. Thus far, erlotinib indications in NSCLC include all subgroups of locally advanced or metastatic NSCLC after failure of at least one prior chemotherapy regimen. In this context, erlotinib treatment improves OS and patient QoL. Erlotinib was clinically developed in parallel with the recent recognition of EGFR as a marker of response to TKIs. There is no doubt that NSCLC patients harboring EGFR mutations have a biologically different entity that requires personalized treatment strategies, including the use of TKIs instead of the unselective chemotherapy. Therefore, erlotinib clinical research has moved from second to first line, and at present, ongoing phase III trials aim to find out if erlotinib can be considered a new standard option in first-line intervention for patients harboring EGFR mutations. On the other hand, maintenance approach has recently received great attention as a suitable option in advanced NSCLC. Based on the results of the pivotal SATURN phase III trial, erlotinib as monotherapy has just been approved for patients with advanced NSCLC with non-progressive (FDA) or stable disease (EMEA), after first-line platinum-based initial chemotherapy. However, there still has been little movement toward accepting maintenance chemotherapy after first-line treatment, and many detractors cite the negligible survival benefit as the key reason. More convincing evidence for this approach could come from a prospective trial comparing the maintenance strategy with the same drug administered soon after first-line chemotherapy completion or after a demonstrated disease progression as a second line. Nevertheless, the concept of giving patients an oral, generally well-tolerated therapy such as erlotinib may be more appealing in the maintenance setting than more standard IV chemotherapy. To date, the SATURN trial, designed to test the role of erlotinib as maintenance treatment after initial 
chemotherapy, is the only randomized trial to demonstrate a significant survival advantage of maintenance with the use of a targeted agent. Unfortunately, most of the absolute advantages reported represent a restricted progress in the treatment of advanced NSCLC. Efforts have to be focused on identifying molecular predictive markers for a selective, rather than indiscriminate, treatment in NSCLC.

\section{Disclosures}

The authors have no conflicts of interest to disclose.

\section{References}

1. Moyer JD, Barbacci EG, Iwata KK, et al. Induction of apoptosis and cell cycle arrest by CP-358,774, an inhibitor of epidermal growth factor receptor tyrosine kinase. Cancer Res. 1997;57:4838-4848.

2. Pollack VA, Savage DM, Baker DA, et al. Inhibition of epidermal growth factor receptor-associated tyrosine phosphorylation in human carcinomas with CP-358,774: dynamics of receptor inhibition in situ and antitumor effects in athymic mice. J Pharmacol Exp Ther. 1999;291:739-748.

3. Dancey J, Sausville EA. Issues and progress with protein kinase inhibitors for cancer treatment. Nat Rev Drug Discov. 2003;2:296-313.

4. Salomon DS, Brandt R, Ciardiello F, Normanno N. Epidermal growth factor-related peptides and their receptors in human malignancies. Crit Rev Oncol Hematol. 1995;19:183-232.

5. EPARs for authorised medicinal products for human use, EMEA. wwwemaeuropaeu/humandocs/Humans/EPAR/tarceva/tarcevahtm Accessed March 2, 2010.

6. US Food and Drug Administration, FDA. www.accessdatafdagov/ Scripts/cder/DrugsatFDA/indexcfm?fuseaction=SearchDrugDetails Accessed March 2, 2010.

7. Vincent MD. Optimizing the management of advanced non-small-cell lung cancer: a personal view. Curr Oncol. 2009;16:9-21.

8. Jemal A, Siegel R, Ward E, et al. Cancer statistics, 2008. CA Cancer J Clin. 2008;58:71-96.

9. Bunn PA Jr, Kelly K. New chemotherapeutic agents prolong survival and improve quality of life in non-small cell lung cancer: a review of the literature and future directions. Clin Cancer Res. 1998;4:1087-1100.

10. Schiller JH, Harrington D, Belani CP, et al. Comparison of four chemotherapy regimens for advanced non-small-cell lung cancer. $N$ Engl J Med. 2002;346:92-98.

11. Scagliotti GV, Parikh P, von Pawel J, et al. Phase III study comparing cisplatin plus gemcitabine with cisplatin plus pemetrexed in chemotherapy-naive patients with advanced-stage non-small-cell lung cancer. J Clin Oncol. 2008;26:3543-3551.

12. Sandler A, Gray R, Perry MC, et al. Paclitaxel-carboplatin alone or with bevacizumab for non-small-cell lung cancer. $N$ Engl $J$ Med. 2006;355:2542-2550.

13. Reck M, von Pawel J, Zatloukal P, et al. Phase III trial of cisplatin plus gemcitabine with either placebo or bevacizumab as first-line therapy for nonsquamous non-small-cell lung cancer: AVAil. J Clin Oncol. 2009;27:1227-1234.

14. Pirker R, Pereira JR, Szczesna A, et al. Cetuximab plus chemotherapy in patients with advanced non-small-cell lung cancer (FLEX): an openlabel randomised phase III trial. Lancet. 2009;373:1525-1531.

15. American Society of Clinical Oncology Clinical Practice Guidelines Update on Chemotherapy for Stage IV Non-Small Cell Lung Cancer. www.ascoorg/guidelines/nsclc. Accessed March 2, 2010.

16. Gatzemeier U, Pluzanska A, Szczesna A, et al. Phase III study of erlotinib in combination with cisplatin and gemcitabine in advanced non-small-cell lung cancer: the Tarceva Lung Cancer Investigation Trial. J Clin Oncol. 2007;25:1545-1552.
17. Shepherd FA, Dancey J, Ramlau R, et al. Prospective randomized trial of docetaxel versus best supportive care in patients with non-small-cell lung cancer previously treated with platinum-based chemotherapy. J Clin Oncol. 2000;18:2095-2103.

18. Shepherd FA, Rodrigues Pereira J, Ciuleanu T, et al. Erlotinib in previously treated non-small-cell lung cancer. $N$ Engl $J$ Med. 2005;353:123-132.

19. Hanna N, Shepherd FA, Fossella FV, et al. Randomized phase III trial of pemetrexed versus docetaxel in patients with non-small-cell lung cancer previously treated with chemotherapy. J Clin Oncol. 2004;22:1589-1597.

20. Ciuleanu T, Brodowicz T, Zielinski C, et al. Maintenance pemetrexed plus best supportive care versus placebo plus best supportive care for non-small-cell lung cancer: a randomised, double-blind, phase 3 study. Lancet. 2009;374:1432-1440.

21. Lynch TJ, Bell DW, Sordella R, et al. Activating mutations in the epidermal growth factor receptor underlying responsiveness of non-small-cell lung cancer to gefitinib. $N$ Engl $J$ Med. 2004;350:2129-2139.

22. Pao W, Miller V, Zakowski M, et al. EGF receptor gene mutations are common in lung cancers from "never smokers" and are associated with sensitivity of tumors to gefitinib and erlotinib. Proc Natl Acad Sci U S A. 2004;101:13306-13311.

23. Paez JG, Janne PA, Lee JC, et al. EGFR mutations in lung cancer: correlation with clinical response to gefitinib therapy. Science. 2004;304: $1497-1500$.

24. Gazdar AF. Activating and resistance mutations of EGFR in non-smallcell lung cancer: role in clinical response to EGFR tyrosine kinase inhibitors. Oncogene. 2009;28 Suppl 1:S24-S31.

25. Bazley LA, Gullick WJ. The epidermal growth factor receptor family. Endocr Relat Cancer. 2005;12 Suppl 1:S17-S27.

26. Kumar A, Petri ET, Halmos B, Boggon TJ. Structure and clinical relevance of the epidermal growth factor receptor in human cancer. J Clin Oncol. 2008;26:1742-1751.

27. Ciardiello F, Tortora G. EGFR antagonists in cancer treatment. $N$ Engl J Med. 2008;358:1160-1174.

28. Gazdar AF, Minna JD. Deregulated EGFR signaling during lung cancer progression: mutations, amplicons, and autocrine loops. Cancer Prev Res (Phila Pa). 2008;1:156-160.

29. Ekstrand AJ, Sugawa N, James CD, Collins VP. Amplified and rearranged epidermal growth factor receptor genes in human glioblastomas reveal deletions of sequences encoding portions of the $\mathrm{N}$ - and/or C-terminal tails. Proc Natl Acad Sci U S A. 1992;89:4309-4313.

30. Shigematsu H, Gazdar AF. Somatic mutations of epidermal growth factor receptor signaling pathway in lung cancers. Int $J$ Cancer. 2006;118:257-262.

31. Mitsudomi T, Kosaka T, Yatabe Y. Biological and clinical implications of EGFR mutations in lung cancer. Int J Clin Oncol. 2006;11:190-198.

32. Tanaka T, Matsuoka M, Sutani A, et al. Frequency of and variables associated with the EGFR mutation and its subtypes. Int $J$ Cancer. 2010;126:651-655.

33. Sordella R, Bell DW, Haber DA, Settleman J. Gefitinib-sensitizing EGFR mutations in lung cancer activate anti-apoptotic pathways. Science. 2004;305:1163-1167.

34. Arao T, Fukumoto H, Takeda M, Tamura T, Saijo N, Nishio K. Small in-frame deletion in the epidermal growth factor receptor as a target for ZD6474. Cancer Res. 2004;64:9101-9104.

35. Greulich H, Chen TH, Feng W, et al. Oncogenic transformation by inhibitor-sensitive and -resistant EGFR mutants. PLoS Med. 2005;2:e313.

36. Janne PA, Johnson BE. Effect of epidermal growth factor receptor tyrosine kinase domain mutations on the outcome of patients with nonsmall cell lung cancer treated with epidermal growth factor receptor tyrosine kinase inhibitors. Clin Cancer Res. 2006;12:4416s-4420s.

37. Mukohara T, Engelman JA, Hanna NH, et al. Differential effects of gefitinib and cetuximab on non-small-cell lung cancers bearing epidermal growth factor receptor mutations. J Natl Cancer Inst. 2005;97:1185-1194. 
38. Jackman DM, Yeap BY, Sequist LV, et al. Exon 19 deletion mutations of epidermal growth factor receptor are associated with prolonged survival in non-small cell lung cancer patients treated with gefitinib or erlotinib. Clin Cancer Res. 2006;12:3908-3914.

39. Jiang J, Greulich H, Janne PA, Sellers WR, Meyerson M, Griffin JD. Epidermal growth factor-independent transformation of $\mathrm{Ba} / \mathrm{F} 3$ cells with cancer-derived epidermal growth factor receptor mutants induces gefitinib-sensitive cell cycle progression. Cancer Res. 2005;65:8968-8974.

40. Hammerman PS, Janne PA, Johnson BE. Resistance to epidermal growth factor receptor tyrosine kinase inhibitors in non-small cell lung cancer. Clin Cancer Res. 2009;15:7502-7509.

41. Yun CH, Boggon TJ, LiY, et al. Structures of lung cancer-derived EGFR mutants and inhibitor complexes: mechanism of activation and insights into differential inhibitor sensitivity. Cancer Cell. 2007;11:217-227.

42. Rukazenkov Y, Speake G, Marshall G, et al. Epidermal growth factor receptor tyrosine kinase inhibitors: similar but different? Anticancer Drugs. 2009;20:856-866.

43. Speake G, Anderton J, Acheson K, et al. A pharmacological comparison of gefitinib and erlotinib. 97th American Association of Cancer Research Annual Meeting, Washington, DC, USA 2006; poster 3784.

44. Yuza Y, Glatt KA, Jiang J, et al. Allele-dependent variation in the relative cellular potency of distinct EGFR inhibitors. Cancer Biol Ther. 2007;6:661-667.

45. Sequist LV, Joshi VA, Janne PA, et al. Epidermal growth factor receptor mutation testing in the care of lung cancer patients. Clin Cancer Res. 2006; $12: 4403 \mathrm{~s}-4408 \mathrm{~s}$

46. Rosell R, Moran T, Queralt C, et al. Screening for epidermal growth factor receptor mutations in lung cancer. $N$ Engl J Med. 2009;361:958-967.

47. Jackman DM, Miller VA, Cioffredi LA, et al. Impact of epidermal growth factor receptor and KRAS mutations on clinical outcomes in previously untreated non-small cell lung cancer patients: results of an online tumor registry of clinical trials. Clin Cancer Res. 2009;15: 5267-5273.

48. Sequist LV, Martins RG, Spigel D, et al. First-line gefitinib in patients with advanced non-small-cell lung cancer harboring somatic EGFR mutations. J Clin Oncol. 2008;26:2442-2449.

49. Paz-Ares L, Soulieres D, Melezinek I, et al. Clinical outcomes in nonsmall-cell lung cancer patients with EGFR mutations: pooled analysis. J Cell Mol Med. 2009 Dec 8. [Epub ahead of print]

50. Mok TS, WuYL, Thongprasert S, et al. Gefitinib or carboplatin-paclitaxel in pulmonary adenocarcinoma. $N$ Engl J Med. 2009;361:947-957.

51. Inoue A, Kobayashi K, Usui K, et al. First-line gefitinib for patients with advanced non-small-cell lung cancer harboring epidermal growth factor receptor mutations without indication for chemotherapy. J Clin Oncol. 2009;27:1394-1400.

52. Morita S, Okamoto I, Kobayashi K, et al. Combined survival analysis of prospective clinical trials of gefitinib for non-small cell lung cancer with EGFR mutations. Clin Cancer Res. 2009;15:4493-4498.

53. Rosell R, Viteri S, Molina MA, Benlloch S, Taron M. Epidermal growth factor receptor tyrosine kinase inhibitors as first-line treatment in advanced nonsmall-cell lung cancer. Curr Opin Oncol. 2009;22: $112-120$.

54. Phase III study $\left(\right.$ Tarceva $\left.^{\circledR}\right)$ vs chemotherapy to treat advanced nonsmall cell lung cancer (NSCLC) in patients with mutations in the TK domain of EGFR (NCT00446225) http://clinicaltrialsgov/. Accessed March 2, 2010.

55. Erlotinib versus gemcitabine/carboplatin in chemo-naive stage IIIB/ IV non-small cell lung cancer patients with epidermal growth factor receptor (EGFR) exon 19 or 21 mutation (ML20981)(NCT00874419) http://clinicaltrialsgov/ Accessed March 2, 2010.

56. Clark GM, Zborowski DM, Santabarbara P, et al. Smoking history and epidermal growth factor receptor expression as predictors of survival benefit from erlotinib for patients with non-small-cell lung cancer in the National Cancer Institute of Canada Clinical Trials Group study BR.21. Clin Lung Cancer. 2006;7:389-394.
57. Pemetrexed or erlotinib as second-line therapy in treating patients with advanced non-small cell lung cancer (NCCTG-N0723). http:// clinicaltrialsgov/. Accessed March 2, 2010.

58. von Plessen C, Bergman B, Andresen O, et al. Palliative chemotherapy beyond three courses conveys no survival or consistent quality-oflife benefits in advanced non-small-cell lung cancer. $\mathrm{Br} J$ Cancer. 2006;95:966-973.

59. Socinski MA, Schell MJ, Peterman A, et al. Phase III trial comparing a defined duration of therapy versus continuous therapy followed by second-line therapy in advanced-stage IIIB/IV non-small-cell lung cancer. J Clin Oncol. 2002;20:1335-1343.

60. Buccheri GF, Ferrigno D, Curcio A, Vola F, Rosso A. Continuation of chemotherapy versus supportive care alone in patients with inoperable non-small cell lung cancer and stable disease after two or three cycles of MACC. Results of a randomized prospective study. Cancer. 1989;63:428-432.

61. Brodowicz T, Krzakowski M, Zwitter M, et al. Cisplatin and gemcitabine first-line chemotherapy followed by maintenance gemcitabine or best supportive care in advanced non-small cell lung cancer: a phase III trial. Lung Cancer. 2006;52:155-163.

62. Park JO, Kim SW, Ahn JS, et al. Phase III trial of two versus four additional cycles in patients who are nonprogressive after two cycles of platinum-based chemotherapy in non small-cell lung cancer. J Clin Oncol. 2007;25:5233-5239.

63. Smith IE, O'Brien ME, Talbot DC, et al. Duration of chemotherapy in advanced non-small-cell lung cancer: a randomized trial of three versus six courses of mitomycin, vinblastine, and cisplatin. J Clin Oncol. 2001;19:1336-1343.

64. Soon YY, Stockler MR, Askie LM, Boyer MJ. Duration of chemotherapy for advanced non-small-cell lung cancer: a systematic review and metaanalysis of randomized trials. J Clin Oncol. 2009;27:3277-3283.

65. Herbst RS, Prager D, Hermann R, et al. TRIBUTE: a phase III trial of erlotinib hydrochloride (OSI-774) combined with carboplatin and paclitaxel chemotherapy in advanced non-small-cell lung cancer. J Clin Oncol. 2005;23:5892-5899.

66. Giaccone G, Herbst RS, Manegold C, et al. Gefitinib in combination with gemcitabine and cisplatin in advanced non-small-cell lung cancer: a phase III trial-INTACT 1. J Clin Oncol. 2004;22:777-784.

67. Herbst RS, Giaccone G, Schiller JH, et al. Gefitinib in combination with paclitaxel and carboplatin in advanced non-small-cell lung cancer: a phase III trial--INTACT 2. J Clin Oncol. 2004;22:785-794.

68. Mok TS, Wu YL, Yu CJ, et al. Randomized, placebo-controlled, phase II study of sequential erlotinib and chemotherapy as first-line treatment for advanced non-small-cell lung cancer. J Clin Oncol. 2009;27:5080-5087.

69. Fidias PM, Dakhil SR, Lyss AP, et al. Phase III study of immediate compared with delayed docetaxel after front-line therapy with gemcitabine plus carboplatin in advanced non-small-cell lung cancer. J Clin Oncol. 2009;27:591-598.

70. Mok TS, Ramalingam SS. Maintenance therapy in nonsmall-cell lung cancer: a new treatment paradigm. Cancer. 2009;115:5143-5154.

71. Jalal SI, Ademuyiwa FO, Hanna NH. The role of maintenance chemotherapy in advanced nonsmall cell lung cancer. Curr Opin Oncol. 2009;21:110-115.

72. Goldie JH, Coldman AJ, Gudauskas GA. Rationale for the use of alternating non-cross-resistant chemotherapy. Cancer Treat Rep. 1982;66:439-449.

73. Cappuzzo F, Ciuleanu T, Stelmakh L, et al. SATURN: A double-blind, randomized, phase III study of maintenance erlotinib versus placebo following nonprogression with first-line platinum-based chemotherapy in patients with advanced NSCLC. J Clin Oncol. 2009;27 Suppl 15: 8001.

74. Miller V, O’Connor P, Soh C, et a1. A randomized, double-blind, placebocontrolled, phase IIIB trial (ATLAS) comparing bevacizumab (B) therapy with or without erlotinib (E) after completion of chemotherapy with B for first-line treatment of locally advanced, recurrent, or metastasic nonsmall cell lung cancer. J Clin Oncol. 2009; 27 Suppl 15:LBA8002. 
75. Cappuzzo F, Coudert B, Wierzbicki R, et al. Efficacy and safety of erlotiniib as first-line maintenance in NSCLC following nonprogression with chemotherapy: results from the phase III SATURN study (abstr A2.1). 13th World Conference on On Lung Cancer, San Francisco. http://www.2009worldlungcancer.org/. Accessed March 2, 2010.

76. Cappuzzo F, Coudert B, Wierzbicki R, et al. Overall survival analyses from the SATURN phase III placebo-controlled study of erlotinib as first-line maintenance therapy in advanced non-small-cell lung cancer (NSCLC). (abstr 22LBA). ECCO 15-34th ESMO Multidisciplinary Congress, Berlin. http:/www.ecco-org.eu/Conferences-and-Events/ ECCO-15-ESMO-34/Abstracts-online/page.aspx/1729. Accessed March 2, 2010.

77. Brugger W, Kim J, Hansen O, et al. Molecular markers and clinical outcome with erlotinib: results from the phase III placebo-controlled SATURN study of maintenance therapy for advanced NSCLC (abstr B9.1) 13th World Conference on On Lung Cancer, San Francisco;Available from: http://www.2009worldlungcancer.org/. Accessed March 2, 2010.

78. Genetech. Press Release ATLAS study. http://www.genecom/gene/ news/press-releases/displaydo? $\operatorname{method}=$ detail\&id $=11827$ Accessed March 2, 2010.

79. Johnson B, Miller V, Amler L. Biomarker evaluation in the randomized, double-blind, placebo-controlled, phase IIIb ATLAS trial, comparing bevacizumab therapy with or without erlotinib, after completion of chemotherapy with B for the treatment of locally-advanced, recurrent, or metastatic non-small cell lung cancer (NSCLC) (abstr 8LBA) ECCO 15-34th ESMO Multidisciplinary Congress, Berlin. http://www.eccoorg.eu/Conferences-and-Events/ECCO-15-ESMO-34/Abstracts-online/ page.aspx/1729. Accessed March 2, 2010.

80. Costa DB, Kobayashi S, Tenen DG, Huberman MS. Pooled analysis of the prospective trials of gefitinib monotherapy for EGFR-mutant non-small cell lung cancers. Lung Cancer. 2007;58:95-103.

81. Engelman JA, Settleman J. Acquired resistance to tyrosine kinase inhibitors during cancer therapy. Curr Opin Genet Dev. 2008;18:73-79.

82. Yun CH, Mengwasser KE, Toms AV, et al. The T790M mutation in EGFR kinase causes drug resistance by increasing the affinity for ATP. Proc Natl Acad Sci U S A. 2008;105:2070-2075.

83. Pao W, Miller VA. Epidermal growth factor receptor mutations, small-molecule kinase inhibitors, and non-small-cell lung cancer: current knowledge and future directions. J Clin Oncol. $2005 ; 23: 2556-2568$.
84. Balak MN, Gong Y, Riely GJ, et al. Novel D761Y and common secondary T790M mutations in epidermal growth factor receptor-mutant lung adenocarcinomas with acquired resistance to kinase inhibitors. Clin Cancer Res. 2006;12:6494-6501.

85. Maheswaran S, Sequist LV, Nagrath S, et al. Detection of mutations in EGFR in circulating lung-cancer cells. $N$ Engl J Med. 2008;359:366-377.

86. Kwak EL, Sordella R, Bell DW, et al. Irreversible inhibitors of the EGF receptor may circumvent acquired resistance to gefitinib. Proc Natl Acad Sci US A. 2005;102:7665-7670.

87. Wong KK, Fracasso PM, Bukowski RM, et al. A phase I study with neratinib (HKI-272), an irreversible pan ErbB receptor tyrosine kinase inhibitor, in patients with solid tumors. Clin Cancer Res. 2009;15: 2552-2558.

88. Janne P, Schellens H, Engelman J, et al. Preliminary activity and safety results from a phase I clinical trial of PF-00299804, an irreversible pan-HER inhibitor, in patients (pts) with NSCLC. J Clin Oncol. 2008; 26 Suppl 15:8027.

89. Miller V, Wakelee H, Lara P, et al. Activity and tolerance of XL647 in NSCLC patients with acquired resistance to EGFR-TKIs: Preliminary results of a phase II trial. J Clin Oncol. 2008;26 Suppl 15:8028.

90. Engelman JA, Zejnullahu K, Mitsudomi T, et al. MET amplification leads to gefitinib resistance in lung cancer by activating ERBB3 signaling. Science. 2007;316:1039-1043.

91. Guix M, Faber AC, Wang SE, et al. Acquired resistance to EGFR tyrosine kinase inhibitors in cancer cells is mediated by loss of IGFbinding proteins. J Clin Invest. 2008;118:2609-2619.

92. Morgillo F, Woo JK, Kim ES, Hong WK, Lee HY. Heterodimerization of insulin-like growth factor receptor/epidermal growth factor receptor and induction of survivin expression counteract the antitumor action of erlotinib. Cancer Res. 2006;66:10100-10111.

93. O'Reilly KE, Rojo F, She QB, et al. mTOR inhibition induces upstream receptor tyrosine kinase signaling and activates Akt. Cancer Res. 2006;66:1500-1508.

94. Rosell R, Viteri S, Molina MA, Benlloch S, Taron M. Epidermal growth factor receptor tyrosine kinase inhibitors as first-line treatment in advanced nonsmall-cell lung cancer. Curr Opin Oncol. 2010;22: $112-120$.

95. Jackman D, Pao W, Riely GJ, et al. Clinical definition of acquired resistance to epidermal growth factor receptor tyrosine kinase inhibitors in non-small-cell lung cancer. J Clin Oncol. 2010;28:357-360.

96. Mok TS. Living with imperfection. J Clin Oncol. 2010;28:191-192.
Cancer Management and Research

\section{Publish your work in this journal}

Cancer Management and Research is an international, peer-reviewed open access journal focusing on cancer research and the optimal use of preventative and integrated treatment interventions to achieve improved outcomes, enhanced survival and quality of life for the cancer patient. The journal welcomes original research, clinical \& epidemiological

\section{Dovepress}

studies, reviews \& evaluations, guidelines, expert opinion \& commentary, case reports \& extended reports. The manuscript management system is completely online and includes a very quick and fair peerreview system, which is all easy to use. Visit http://www.dovepress.com/ testimonials.php to read real quotes from published authors. 